\title{
TAXPAYER BEHAVIOR: TYPES OF TAXPAYERS CREATED THROUGH TAX SANCTIONS AND INCENTIVES
}

\author{
Nazan SUSAM ${ }^{1}$
}

\author{
Filiz BALOĞLU²
}

\begin{abstract}
As with all economic activities of individuals, tax compliance or incompliance is also built with social, cultural and psychological factors. From the complexity of the tax system to the tax penalties, from social and demographic factors to moral and social factors, many dynamics take part in this process. Taking into account that the tax policies adopted may always have unintended consequences, the considerations as to what sort of impacts that tax or other factors might have on the tax world carries importance. On the other hand, the regulation of social relations often takes place under uncertainty, as an agent, individuals can react differently to the uncertainty created by formal rules. As a formal rule, tax sanctions or facilities create different effects on taxpayer behavior and create different types of taxpayers within the system. The basic elements underlying the voluntary compliance with tax are the confidence of the taxpayer to and the perceived power of the tax administration. In this framework, efforts paid on how the determinants of taxpayers' tax payment or non-payment tendencies affect tax compliance process and classification of taxpayers types arising from the process.
\end{abstract}

Keywords: Tax Compliance, Tax Noncompliance, Confidence in Tax Administration, Economic Approach, SocioPsychological Approach

JEL Code: H2, H26

In order to explain the tax compliance process it is important to explore how taxation affects human behavior, from socio-political, cultural and social perspectives as well as financial and economic ones. A review of the literature reveals many publications that aspire to do this.

The initial approaches to this subject in the field of financial sociology focus on macro sociological efforts. These developments deal with the role of institutions and classes, the regulating capacity of the state and macro level conflicts of interest as the major factors that define the role and position of the state. Recent studies on the other hand emphasize micro variables such as taxpayers' motivations and strategic decisions, and variables such as social relationships and interactions. There is no doubt that micro variables are sociologically important in this framework and that different interpretations underlie the compliance tendency and behavior of each individual.

Tax compliance is defined as voluntary fulfillment of tax liabilities fully and completely or willingness to pay taxes, while not fulfilling these liabilities is called tax noncompliance. What needs to be noted in this framework is that, tax compliance implies behaving in accordance with the letter and spirit of the law, without any need for force (James and Alley, 2002: 32, Saruç,

\footnotetext{
1 Prof. Dr., Istanbul University, Faculty of Economics, Department of Public Finance, nsusam@istanbul.edu.tr

2 Asst. Prof. Dr., Istanbul University, Faculty of Economics, Department of Economics, Economic Sociology, fbaloglu@istanbul.edu.tr
} 
2015: 23). Indeed, it is found that historically when compliance involves willingness the taxation of construction process is healthy, while constant interventions that reorganize the compliance process are needed in societies where it does not. After all, tax sanctions and incentives (TSIs) can be considered an indication of these interventions.

The literature on compliance has been created mainly by economists who emphasize dissuasiveness and sociologists who emphasize social norms in the context of social limitations as critical factors that affect tax paying behavior (Roth, Scholz and Witte, 1989). The economic approach, which views the taxpayer as a rational individual, Assoc.s tax compliance with economic factors and the factor that motivates the decision of the taxpayer has been reduced to a cost-benefit analysis. In the economic model dissuasiveness, related to monetary penalties and probability of inspection, is highlighted. In this context, factors such as income levels, tax rates, probability of inspection and penal sanctions are more influential on taxpayers' decisions to pay taxes or not.

Although the economic approach reveals an important issue, other studies have pointed out the limitations of attributing tax compliance behavior merely to economic factors, and it is these deficiencies and limitations that have laid the grounds for sociological and psychological approaches to tax compliance. The psychological approach traditionally considers the effects of norms on tax compliance in the scope of the theory ofmoral emotions, focusing on individual socio-psychological variables such as moral beliefs, attitudes and perceptions about tax compliance (Alm et al., 1995; Bobek, Hageman and Kelliher, 2013: 451). The sociological approach on the other hand, focuses on the importance of social limitations and norms in managing noncompliance to taxes and other laws. The impact of socialization is higher than the impact of conscious action on individual behavior and what is considered moral behavior in terms of compliance is dictated by internalized norms.

When factors that affect the compliance process are evaluated with these approaches each has distinctive effects. Yet, when the process of tax compliance is considered to be the complete set of relationships between the state and the individual, it can be explained by considering different factors. Through these factors it is possible to see how the tax compliance process is constructed with a focus on the taxpayer and the state.

Both positive and negative relationships can be found between all of these factors and tax compliance and it is possible to say that social and psychological factors are the main source of this relationship.

Considering the perspective brought by economic sociology together with economic and psychological approaches, it might be possible to reach a holistic perspective towards the statetaxpayer relationship, since the taxpayers' social connections lie behind their tax compliance behavior. And the marks of these connections can be seen in the relations and interactions of the taxpayer with other taxpayers, with the state and even with the society as a whole.

What will be the direction of the interaction that determines this relationship? Cooperation or conflict? Relationships based on trust or on power?

The way that the state obtains the financial resources it needs to fulfill its functions is reflective of the profile of its relationship with individuals. The response of a society to the taxation system and the tax authorities is multidimensional and not constant, and therefore it is necessary to examine the social relations as much as the technical and administrative processes (Braithwaite, 2002: 16). 
Taxation represents the area where this tacit agreement between the state and the individual becomes visible and is the product of co-existence as a society. The state-taxpayer and taxpayertaxpayer interactions are shaped in the realm of taxes that include formal and informal rules, duties and rights.

When taxation is viewed as a dynamic relationship between the taxpayer and the state, this relationship always carries a potential for conflict. This conflict stems from the fact that the state-taxpayer relationship operates in a covert/hidden disorder. Therefore, the state is always in search of new rules to be able to manage the noncompliance process of the taxpayers. The state authority, which is the warrantor of social order in the modern world, tries to respond to this potential for conflict with new forms and rules of taxation (Martin, Mehrotra and Prasad, 2009: 3). In this framework, sanctions and incentives can be considered new forms of these ever changing rules.

Another interaction between the state and the taxpayer in terms of tax compliance is related to the factors of trust and power. It is possible to say that the state, which holds the substantial portion of power, has a more concrete and visible role in establishing trust. However, since interaction cannot be in one direction, it is important not to neglect the role of the taxpayer in the establishment of trust.

When tax compliance is examined from the perspective of trust, socio-psychological influences gain importance and the analysis is predicated on issues such as justice, transparency, convenience of the process, the clarity of the system, determination of the rights of the taxpayers and the taxpayer having a voice, as the determinants of trust towards the tax administration.

The factor of power, on the other hand, is determined according to the inspection and punishment potential of the tax administration and is related to the degree to which the taxpayer feels this power, the sanctions, the probability of inspection, the probability of penalty and the severity of the penalty. In this framework, the main indicator of the power of the tax administration is the sanctions it applies (Tyler 2001: 233-234).

When we look at the Turkish taxation system, the sanctions applied to the taxpayer, the tax responsible party or other concerned parties are monetary sanctions (financial penalties), restriction of freedom, deprivation of rights or public disclosure of names (Şenver, 2017: 93-94). Tax incentives on the other hand include tax amnesties, reconciliation, exemption and exceptions, tax deferrals and statute of limitations. These are all considered efforts towards increasing tax compliance. However, tax sanctions and incentives do not always lead to the expected results or help create the desired type of taxpayer.

The role of TSIs in the system, the intervals between their use and the frequency of changes in them will determine the direction of the interaction between the state and the taxpayer. If social organization, institutional structures, the civic and technical environment of daily life is continuous and balanced, and if these continue to operate regularly and predictably in times of change, then it is likely that a culture of trust and therefore tax compliance will be achieved (Sztompka, 1997: 13). Contrarily, as demonstrated by applications of tax amnesties and reductions, frequent changes and repetitions accelerate the loss of that culture.

The taxation system of a country and the TSIs in that system, as explained above, are linked to a number of factors that are determined by economic and socio-psychological approaches and cause certain responses and behaviors among taxpayers against taxes. The consequences 
of taxpayers' behavior are categorized using various methods and certain taxpayer typologies are identified accordingly.

These taxpayer typologies we try to identify in this study are based on the tendencies of the taxpayers in the face of TSIs. The interaction that emerges between actors as a result of TSIs and taxpayers' behavior in response to each situation based on the determinants that support this interaction lead to these typologies.

The direction of interaction is based on the factors of conflict, cooperation, trust, power and pressure. Conflict and cooperation determines the form of interaction between the state and the taxpayer. Conflict is an ordinary part of social life. Since actors in a society compete for resources, their interests are organized by conflict rather than norms and values. Although conflict seems negative, since it involves opposing views, it can turn the direction of interaction towards cooperation by allowing the rules of the taxation system to change. Cooperation might arise without raising any conflict, or as the result of conflict.

Trust and power on the other hand are the social mechanisms that organize these forms of interaction. Establishment of trust is important because it will popularize behavior that leans towards cooperation and actors develop mutually. However, since the state and the taxpayers will look out for their own interests, there will be a constant struggle of power. Powerful actors will be able to gain advantage by applying pressure on others.

In the light of these insights, we can identify there types of taxpayers:

The first type is the obligated compliant taxpayers, which arise because sanctions create an atmosphere of conflict and highlight the factor of power, and taxpayers tend to pay more because they feel pressure.

Secondly, when there is a shift from sanctions to incentives in the interaction between the state and the taxpayer, an atmosphere of cooperation is created where a taxpayer-centered understanding develops and the complianttaxpayer type emerges.

Third, when applications like tax amnesties and reductions lead to a combination of conflict and cooperation, and cause the factors of power and trust to operate together, it leads to the strategic taxpayer type to emerge, which behave strategically, according to their expectations.

\section{Conclusion}

Knowing what taxpayers want is a significant advantage for the authority. One of the fundamental reasons for the ineffectiveness of many authoritarian governments is known to be the lack of information on people's preferences. The more pressure is applied the less the government will learn about the citizens' preferences and opinions about the government, and the harder it will be to build a relationship of trust. People or institutions, even if they are honest, will attempt to avoid their tax liabilities if they do not believe that the government will not respond to their demands. Therefore, governments need information about the services that the citizens expect in order to be able to respond to these demands, and the people need motivation that these services will be provided (Wintrobe, 2001: 13). Where trust between the taxpayer and the state is high, the costs of economic actions will be reduced and tax revenues will increase, since people's behavior can be foreseen (Knack and Keefer, 1997: 1252). 


\section{References}

Alm, J., Sanchez, I. \& De Juan, A. (1995). "Economic and Non-Economic Factors in Tax Compliance", 48 (1), KYKLOS, pp. 3-18.

Bobek, D. D., Hageman, A. M. \& Keeliher, C. H. (2013). "Analyzing the Role of Social Norms in Tax Compliance Behavior", Journal of Business Ethics, 115, pp. 451-468.

Braitwaite, V. (2002). "Dancing with Tax Authorities: Motivational Postures and Non-Compliant Actions", (Ed.) V. Braithwaite, Taxing Democracy: Understanding Tax Avoidance and Evasion, Ashgate, Aldershot, pp. 15-40.

James, S. \& Alley, C. (2002), "Tax Compliance, Self-Assesment and Tax Administration", Journal of Finance and Management in Public Services, 2 (2), pp. 27-42.

Knack, S. \& Keefer P. (1997), "Does Social Capital Have an Economic Payoff? A Cross Country Investigation", The Quarterly Journal of Economics, 112 (4), pp. 1252-1288.

Martin, I. W., Mehrotra, Ajay K. \& Prasad, M. (2009). "The Thunder of History: The Origins and Developments of the the New Fiscal Sociology", The New Fiscal Sociology, Taxation in Comparative and Historical Perspective, Cambridge, Cambridge University Press, pp. 1-27.

Roth, J., Scholz, J. T. \& Witte, A. D. (1989). Taxpayer Compliance: An Agenda for Research, Vol. I, Philadelphia, University of Pennsylvania Press.

Sztompka, P. (1997), "Trust, Distrust and The Paradox of Democracy", Wissenschaftszentrum Berlin für Sozialforschung gGmbH (WZB) Reichpietschufer 50, p97-003, D-10783, 3-13, Berlin, http: //bibliothek.wz-berlin.de/pdf/1997/p97-003.pdf, (23.12.2007).

Tyler, T. R. (2001), "Public Trust and Confidence in Legal Authorities: What do Majority and Minority Group Members Want from the Law and Legal Institutions?", Behavioral Sciences and The Law 19 (2), pp. 215-235.

Wintrobe, R. (2001). "Tax Evasion and Trust", UWO Department of Economics Working Paper, University of Western Ontario, Deparment of Economics, 200111, pp. 1-23. 